\title{
ELENA CAFFARENA DE JILES, JURISTA
}

\author{
María Sara Rodríguez Pinto*
}

\begin{abstract}
RESUMEN: Perfil biográfico de una destacada abogada del siglo XX. La autora resalta las pasiones políticas y sociales que ocuparon su vida. Enfatiza su interés por los casos reales y por la evolución de la jurisprudencia; y también la naturaleza de sus publicaciones como escritos de tesis.
\end{abstract}

Palabras clave: Mujeres chilenas, juristas, sufragio femenino, feminismo chileno, análisis jurisprudencia del derecho.

ABSTRACT: Biographic profile of an outstanding lawyer of the Twentieth Century. The author highlights the political and social passions that occupied her life. She emphasizes her interest for real cases and the evolution she was able to trace and influence in the decisions of Courts; and also the nature of her publications as writings of theses.

Key words: Chilean women, lawyers, women's suffrege, chilean feminism, case-based analysis of the law.

Entre muchas otras conmemoraciones, el 150 aniversario de la promulgación del Código Civil chileno (14 de diciembre de 1855) ha merecido un homenaje a los juristas que han contribuido a forjar una doctrina en torno a sus disposiciones. Entre estos destaca doña Elena Caffarena de Jiles (1903-2003). Es imposible trazar una semblanza de esta mujer sin ofrecer primero algunos rasgos de su perfil biográfico, y de los intereses sociales y políticos que ocuparon su vida. Comenzaré, entonces, con esto. A continuación, intentaré delinear los caracteres de su labor como jurista y los aportes que a mi juicio debemos agradecer a sus estudios.

\section{PERFIL BIOGRÁFICO}

Elena Caffarena Morice nace en Iquique en 1903 y fallece en Santiago el 19 de julio de 2003, a la edad de 100 años y, según testimonios de la época, en pleno uso de sus facultades mentales. Es hija de don Blas Caffarena, inmigrante italiano de ascendencia genovesa, y de doña Ana Morice. Ocupa un número entre los siete hijos del matrimonio (cinco mujeres "con fama de bonitas" y dos hombres). Cuando tiene 17 años, la familia se traslada a vivir a Santiago, donde -con máquinas y técnicas que trae de Filadelfia- su padre funda en 1920 la industria de tejidos que lo hace famoso. A los 20 años Elena es activa militante de la Federación de Estudiantes de Chile (Fech), participa en el Servicio de Asistencia Jurídica Gratuita de su Facultad y protagoniza sus primeras incursiones en política.

Licenciada en Derecho por la Universidad de Chile en 1926; es una de las 15 primeras mujeres juristas de Chile. En 1929 contrae matrimonio con Jorge Jiles Pizarro,

${ }^{*}$ Profesora de Derecho Civil, Universidad de los Andes. 
abogado vinculado al Partido Comunista y posteriormente senador. Comparte con Jiles el hogar y la oficina hasta su muerte, y tiene con él tres hijos. Si bien es mujer inteligente, preparada, independiente y procedente de una familia con prestigio social, es indudable la influencia de las ideas sociales y políticas del marido en su pensamiento y en su acción.

La vida de Elena Caffarena de Jiles -como siempre prefirió firmar- transcurrió, en efecto, muy vinculada a las vicisitudes del mundo de la izquierda y, posiblemente, su pensamiento se va radicalizando con los años. Simultáneamente, tanto ella como su marido asesoran legalmente a la empresa familiar como abogados. En los años '40, Jiles incluso asume la gerencia y con preclara intuición levanta notablemente el negocio. Elena nunca fue militante del Partido Comunista, pero en palabras de don Patricio Aylwin, parece haber profesado "simpatía y aun devoción por el régimen soviético"1. Los Caffarena Jiles, por tanto, si bien ideológicamente vinculados al Partido Comunista, socialmente pertenecen a la burguesía; y gozan de una vida acomodada.

Como datos que completan su biografía podemos agregar que fue tía de Ricardo Izurieta Caffarena, Comandante en Jefe del Ejército y primo del que actualmente ocupa el mismo cargo. Izurieta Caffarena es hijo de su hermana menor, Victoria, y del general de Ejército Pelayo Izurieta Molina. Este último, hermano de Oscar Izurieta Molina, también militar y Comandante en Jefe del Ejército bajo el gobierno de Alessandri. Es también abuela de Pamela Jiles, periodista.

\section{INTERESES SOCIALES Y POLÍTICOS: IMPULSORA DEL SUFRAGIO FEMENINO}

Elena Caffarena tuvo dos grandes pasiones sociales y políticas: el sufragio femenino y la asistencia social de mujeres y niños.

Fue, en efecto, gran impulsora de la plena incorporación de la mujer a la vida política, causa a la que dedicó muchos años de apasionado activismo. En los años '30 la familia Caffarena Jiles realiza un viaje por Europa del que Elena vuelve convencida de la causa sufragista. En 1935 es fundadora y primera secretaria general del Movimiento de Emancipación de la Mujer Chilena (Memch) (1935-1941), cuya gran bandera de lucha es el sufragio femenino. En 1941 Pedro Aguirre Cerda presenta al Congreso un proyecto que confiere plenos derechos políticos a las mujeres. El proyecto es redactado por Flor Heredia y Elena Caffarena. En 1944 funda la Federación Chilena de Instituciones Femeninas (Fechif), organización de la que es primera vicepresidenta y a través de la cual impulsa una gran campaña nacional reivindicando los derechos políticos de las mujeres chilenas. En junio de 1945, la Fechif presenta al Senado un nuevo proyecto de ley sobre voto femenino, en cuya redacción interviene directamente la jurista. El proyecto tiene una historia compleja que, sin embargo, no termina con el cambio de gobierno. El 8 de enero de 1949, poco tiempo después de asumir como presidente, Gabriel González Videla lo promulga. Flor Heredia, Elena Caffarena y otras mujeres sufragistas chilenas

\footnotetext{
${ }^{1}$ Prólogo de Patricio Aylwin Azócar, en: Caffarena de Jiles (1957) p. 9.
} 
son excluidas de los actos conmemorativos. Tres días después el gobierno cancela su inscripción en los registros electorales. Ella lo cuenta así:

Pocos días después, González Videla canceló mi inscripción en los registros electorales aplicándome la "Ley Maldita", porque yo defendia, en mi calidad de abogada, a cuarenta mujeres y sus más de cien hijos menores de edad que estaban prisioneros en el campo de concentración de Pisagua. Su único delito - de las madres- era pensar distinto que el primer mandatario... El de los niños era, supongo, el de ser hijos de esas madres. Fui acusada entonces de comunista, de agitadora, de cabecilla de una revuelta... y me proscribieron ${ }^{2}$.

Las mujeres votan por primera vez en las elecciones presidenciales de 1952, año en que sale a la luz su estudio sobre las sufragistas inglesas del XIX: Un capitulo en la historia del feminismo: las sufragistas inglesas (Santiago: Ediciones del Memch, 1952, 113 pp.). Es indudable que, a esas alturas, la autora considera cerrado el capítulo del sufragio.

En forma simultánea con su militancia sufragista y feminista, desarrolla también una intensa actividad en el ámbito de la protección de menores. En 1940 el Presidente Pedro Aguirre Cerda la nombra como representante del gobierno en el directorio del Consejo de Defensa del Niño, institución a la que entrega toda una vida de dedicación, hasta 1974 en que es separada del cargo. Su generosidad la mueve incluso a donar una casa a esta institución para el cobijo de cuarenta menores. En 1979 es fundadora y primera vicepresidenta de la Fundación para la Protección de la Infancia Dañada por los Estados de Emergencia, destinada a socorrer a niños y adolescentes víctimas directas o indirectas del exilio y la relegación.

En todas estas empresas, doña Elena vuelca su trabajo como abogada, su ingenio y su entera capacidad. Pero su prestigio como jurista no obedece al ejercicio activo de la profesión de abogada, ni a las causas políticas y sociales que defiende con pasión. Aunque práctica y amiga de resultados tangibles, posee una inteligencia penetrante y argumenta con elocuencia y erudición. Llega el momento de hablar, entonces, de su perfil como jurista.

\section{INTERESES JURÍDICOS}

Los intereses jurídicos de doña Elena Caffarena de Jiles están, a mi juicio, marcados por dos coordenadas. La autora demuestra, en primer lugar, ser jurista dotada de una gran visión práctica y maestra del tratamiento jurisprudencial del Derecho. La segunda coordenada de su perfil como jurista es el carácter de su obra como escrito de tesis, género que privilegia por sobre las obras de tratamiento expositivo, dogmático o pedagógico. En lo que resta de esta semblanza explicaré estos dos rasgos de su vocación como jurista. Terminaré recordando su memoria de licenciatura, que la puso en contacto con la tradición del derecho civil, con las obras de los grandes tratadistas franceses y con el derecho romano.

2 Palabras de su autobiografía citadas por Pamela Jiles, en la revista Punto Final $N^{\circ} 539$ disponible en http://www.puntofinal.cl/539/). 


\section{LA RECONSTRUCCIÓN DEL DERECHO DESDE EL CASO Y LOS GRUPOS DE CASOS}

Doña Elena Caffarena de Jiles fue una atenta observadora -y en muchos casos incluso protagonista- de la evolución de la jurisprudencia, de la actividad de los tribunales y de las doctrinas judiciales en boga. Su obra está impregnada de esta conexión con la realidad práctica, sin la cual el derecho es ineficaz o doctrina de laboratorio. Son los casos y los fallos lo que pone en marcha su actividad investigadora. Veamos algunos ejemplos.

Schortz de Coleman con Coleman ${ }^{3}$, caso en el que la Corte Suprema acoge el recurso de casación interpuesto por el marido contra la sentencia que segunda instancia que hace lugar a la demanda de alimentos de la mujer separada de hecho, le recuerda Basso de Sampen con Sampen ${ }^{4}$, que establecía la misma doctrina, considerando infringido un precepto legal inexistente. Su convicción del error en que incurría la Corte Suprema al negar este derecho la conduce a examinar todos los fallos sobre alimentos entre cónyuges publicados por la Gaceta de los Tribunales desde sus inicios. Descubre así que los tribunales nunca han rechazado la demanda del marido que pide alimentos por el hecho de vivir fuera del hogar conyugal. Es decir, aplican un criterio para rechazar la demanda de la mujer separada contra el marido y otro para acoger la demanda del marido separado contra su mujer.

La perplejidad en que la deja esta errática doctrina la lleva a examinar en toda su extensión la obligación de alimentos entre cónyuges en los autores franceses y chilenos; y las diferencias entre el Código francés y el nuestro en la materia. Una es la obligación de socorro entre los cónyuges y otra la de alimentos, concluye. Si bien ambas obligaciones persiguen la misma finalidad, la sustentación de los cónyuges, los supuestos de hecho en que operan estas diversas obligaciones difieren. La obligación de socorro supone un normal funcionamiento del matrimonio; la obligación de alimentos, en cambio, supone un quiebre y, naturalmente, la necesidad del alimentario. No hay ley que permita negar a la mujer los alimentos que necesita. Máxime cuando no se le niegan al marido que, cumplidos los requisitos legales, los pide a su mujer, aun cuando en algún caso la mujer se excepciona alegando la capacidad del marido para trabajar y sus reducidas facultades con doce hijos que alimentar, un trabajo y un hogar que mantener. Son estos los casos y argumentos que defiende en ¿Debe el marido alimentos a la mujer que vive fuera del hogar conyugal? (Santiago, 1944), obra que recibe el premio Manuel Egidio Ballesteros y un elogioso prólogo de don Luis Barriga Errázuriz, quien se declara convencido de las tesis de la autora pese a su anterior reticencia.

La sentencia de la Corte Suprema en Montes con Roldán 5 , que acoge la acción del marido para que su mujer sea obligada con el auxilio de la fuerza pública a reintegrarse al hogar común, pone en marcha su estudio sobre la incoercibilidad de gran parte de los derechos y obligaciones personales del Derecho de familia. (“`Puede usarse la fuerza públi-

\footnotetext{
3 Schortz de Coleman con Coleman (1939).

${ }^{4}$ Basso de Sampen con Sampen (1937).

${ }^{5}$ Montes con Roldán (1948).
} 
ca para el cumplimiento de la obligación prevista en el artículo 133 del Código civil?”, Revista de Derecho y Jurisprudencia). Los hechos que motivan el fallo de casación son los siguientes: la mujer demanda al marido la nulidad del matrimonio. Este reconviene para que se declare que la mujer está obligada a restituirse al hogar común y prestarle la fe, el socorro, la ayuda y la obediencia debida, dentro de tercero día de ejecutoriada la sentencia. La Corte de Apelaciones confirma la sentencia que niega lugar a esta acción. Se funda en que las obligaciones personales entre cónyuges no pueden exigirse por la fuerza. La Corte Suprema, en cambio jacoge el recurso de casación interpuesto por el marido! Requerida para ello la justicia, piensa el voto de mayoría, no puede negar la declaración de un derecho (aunque sea luego en la práctica imposible de exigir coercitivamente). Las obligaciones del artículo 133 no son obligaciones morales sino verdaderas obligaciones civiles. La sentencia tiene voto de minoría firmado por don Rafael Fontecilla y don Urbano Marín, quienes sustentan la opinión de que estos derechos no son susceptibles de coacción. El fallo se publica en la Revista de Derecho y Jurisprudencia con comentario de don Manuel Somarriva, que disiente del voto de mayoría y apoya el de minoría.

Doña Elena, en su comentario, distingue además entre sanción y coerción; y entre obligación y acción. Las obligaciones jurídicas tienen sanción que opera como elemento de intimidación. Algunas de ellas, además, pueden exigirse coercitivamente mediante el empleo de la fuerza pública. Se conocen algunos derechos sin coacción. Las obligaciones derivadas del artículo 133 del Código civil son un ejemplo de esto. Su incumplimiento está sancionado con el divorcio temporal; pero respecto de ellas no cabe coerción. Además, alega Caffarena, hay que distinguir entre obligación y acción. Esta última es una pretensión judicial que se rige por el derecho procesal. No existe en nuestras leyes procesales un procedimiento que permita exigir coercitivamente el cumplimiento de obligaciones personalísimas, pues esto atentaría contra la libertad personal, sostiene. Por tanto, no es posible usar la fuerza pública para exigir el cumplimiento de las obligaciones previstas en el artículo 133 del Código civil.

Su única incursión en Derecho público (El recurso de amparo frente a los regímenes de emergencia, Santiago, 1957) parte también de casos: la línea de fallos en que la Corte Suprema rechaza sistemáticamente los recursos de amparo interpuestos a favor de personas detenidas o relegadas por la autoridad política bajo el imperio de estados de excepción constitucional. Los ministros se escudan, para rechazar estos recursos, en un "lugar común" que doña Elena se ocupa de descuartizar: las detenciones o relegaciones son facultades privativas de la autoridad política que, de conformidad al artículo $4^{\circ}$ del Código Orgánico de Tribunales, no corresponde a los tribunales revisar. La discrecionalidad incluye, por tanto, la arbitrariedad de la autoridad política en el ejercicio de las facultades que le otorgan los estados de excepción constitucional. Sin embargo, de ser así las cosas, demuestra la autora, la misma finalidad del recurso de amparo se vería frustrada y la ley sería letra muerta. Esta obra, elogiosamente prologada por don Patricio Aylwin Azócar, desgraciadamente no encuentra el eco de sus estudios de derecho privado en la jurisprudencia. Se habrían evitado muchos males en Chile si los tribunales hubieran modificado su criterio restrictivo respecto del recurso de amparo en los estados de excepción constitucional. 
Su gusto por el caso y su atento seguimiento de la jurisprudencia queda generosamente demostrado en una de sus últimas obras publicadas: el Diccionario de jurisprudencia chilena: recopilación de conceptos y definiciones (Santiago, 1957). La autora define un extenso catálogo de voces, que van de la $a$ (en "a boca de jarro") a la y (como en "yacer"), en la forma de conceptos y definiciones, y lo ilustra con extractos y citas jurisprudenciales. El libro cuenta con 346 páginas y recoge abundante jurisprudencia chilena de 1903 a 1957 perteneciente a todos los ámbitos del derecho público y privado. El trabajo permite demostrar el seguimiento que la autora hacía de la jurisprudencia de los tribunales y su paciente labor de selección y sistematización de fallos, algo que seguramente realizó por años, día tras día, en una era sin computador. La obra es de tal envergadura que merece una nueva edición en dos volúmenes, realizada por la autora y don Mario Verdugo Marinkovic, en 1984. Verdugo reproduce el formato creado por nuestra jurista actualizando la obra hasta 1983. El primer volumen incluye, además, el catálogo de adagios, aforismos y principios citados en la jurisprudencia chilena, previamente publicado por la autora en 1959; el segundo, obra directa de Verdugo Marinkovic, incluye un apéndice con adagios latinos citados en fallos de los tribunales hasta 1983. Promete el autor, además, continuar esta labor de actualización año a año; promesa que, al parecer, no ha podido cumplir.

Elena Caffarena de Jiles se alza, pues, como jurista de gran destreza práctica y profunda conocedora de la jurisprudencia chilena, siendo este uno de los rasgos característicos de su perfil como jurista. A este se añade el carácter asertivo de sus escritos.

\section{EL ESCRITO DE TESIS}

En efecto, la obra de doña Elena Caffarena de Jiles apunta siempre a la defensa de una tesis. La autora no escribe para ofrecer al lector un aparato dogmático ni erudito, ni para sistematizar la ley por sistematizar. Carece de lo que podríamos llamar el "prejuicio docente". No escribe para enseñar. Escribe para convencer, para polemizar, para corregir doctrinas judiciales que considera erradas. Pero no lo hace por el interés "abogadil" de quien pone "la ley al servicio de conclusiones preestablecidas por medio de habilidosas interpretaciones"6. "No hay nada más anticientífico que la elaboración de una defensa", piensa la autora. Al contrario. Sus tesis "aparece[n como] la consecuencia lógica e ineludible de sólidos raciocinios, basados en el examen de las instituciones que entran en juego" "Sus escritos despiertan interés en el lector y convencen; manejan la jurisprudencia, pero también la doctrina nacional y extranjera más importante a la fecha.

Así, en su ya citado libro ¿Debe el marido alimentos a la mujer que vive fuera del hogar conyugal? (Santiago, 1947) defiende la tesis de que la obligación de alimentos no se suspende por el hecho de la vida separada y que es un error negar este derecho a la mujer que ha dado lugar a la separación por su hecho o culpa; máxime cuando no se niega este derecho al marido en la misma situación. Esta obra "llamada a destacarla con especial relieve entre nuestros juristas, es una de las mejores monografías que hemos

\footnotetext{
${ }^{6}$ Prólogo de Luis Barriga Errázuriz, en: CAFFarena De Jiles (1947), p. 2.

7 Prólogo de Luis Barriga Errázuriz, en: CAFfarena De Jiles (1947), p. 2.
} 
leído -confiesa el prologuista el libro- sin duda alguna, la contribución más completa, nutrida y eficiente que se haya aportado para la solución del problema que plantea la interrogación que le sirve de título"8. Cuando en 1950 la jurisprudencia comienza a darle la razón, vuelve a salir al paso de la resistencia de la doctrina. Así se explica su "Refutación a los comentarios de D. Enrique Rossel Saavedra sobre la jurisprudencia en materia de alimentos", publicada en la Revista de Derecho y Jurisprudencia en 1952. El profesor Rossel comenta críticamente dos sentencias que acogen las tesis de doña Elena acerca de la distinción entre el deber de socorro y la obligación de alimentos entre cónyuges 9 . La autora refuta uno por uno los argumentos del profesor Rossel y vuelve a afirmar su tesis, elogiando la evolución positiva de la jurisprudencia.

En "¿Puede usarse la fuerza pública para el cumplimiento de la obligación prevista en el artículo 133 del Código civil?”, publicado en 1949, defiende con elocuencia y erudición la incoercibilidad de las obligaciones personales derivadas del matrimonio. Por último, la tesis de la plena vigencia y procedencia del recurso de amparo en defensa de la libertad personal durante los estados de excepción constitucional es eficientemente demostrada en 1957. (El asunto la afectaba personalmente, pues su marido había sufrido las consecuencias de numerosos estados de excepción bajo el gobierno de Gabriel González). Son estas también las grandes contribuciones de su obra a la doctrina chilena. La defensa de una tesis es tarea que le apasiona desde su misma memoria de licenciatura.

\section{EL ENRIQUECIMIENTO SIN CAUSA A EXPENSAS DE OTRO EN EL DERECHO CIVIL CHILENO}

Los hábitos intelectuales que perfilan su carácter de jurista provienen, posiblemente, de sus años de juventud. Estos despuntan ya en su memoria de licenciatura sobre el enriquecimiento sin causa (El enriquecimiento sin causa a expensas de otro en el derecho civil chileno, Santiago, 1926). La autora intenta con esta memoria reproducir en Chile la labor precursora que realizaron en Francia Aubry et Rau, a través de su Cours de droit civil d'après la méthode de Zachariae (1838). Es sabido que uno de los grandes temas que transitan de Zachariae (1808) a través de la obra de Aubry et Rau hacia la jurisprudencia francesa es el del enriquecimiento sin causa. Es esta la base doctrinal en la que se apoya la Cour de Cassation para admitir una acción de enriquecimiento sin causa en el derecho francés (que llama actio de in rem verso), a través del famoso Arrêt Boudier de 1892. El método de Zachariae, que reordenó las disposiciones del Code Napoleon según el orden de las Pandectas o según los principios de derecho común en que se inspiran, es el que la autora quiere utilizar para abrir camino a la creación jurisprudencial de una acción de enriquecimiento sin causa en el derecho chileno. No lo logra respecto de la actio de in rem verso, pero sí respecto de interpretaciones erróneas que consigue corregir con su influencia y erudición.

\footnotetext{
${ }^{8}$ Prólogo de Luis Barriga Errázuriz, en: CAFfarena De Jiles (1947), p. 5.

9 Catalán con Pavez (1950); Basualto con Grandona (1951).
} 


\section{BIBLIOGRAFÍA CITADA}

De Elena Caffarena de Jiles:

(1926): El enriquecimiento sin causa a expensas de otro en el derecho civil chileno (Santiago, Imprenta Balcells) 95 pp.

(1944): La capacidad de la mujer casada con relación a sus bienes (Santiago, Imprenta Universitaria) $83 \mathrm{pp}$.

(1947): ¿Debe el marido alimentos a la mujer que vive fuera del hogar conyugal? (Santiago, Ediciones de la Universidad de Chile) 297 pp.

(1949): “¿Puede usarse la fuerza pública para el cumplimiento de la obligación prevista en el artículo 133 del Código Civil?”, Revista de Derecho y Jurisprudencia, t. 46, pp. 82-94

(1952): "Refutación a los comentarios de don Enrique Rossel Saavedra sobre la jurisprudencia en materia de alimentos", Revista de Derecho y Jurisprudencia, t. 49, pp. 21-34.

(1952): Un capitulo en la historia del feminismo: las sufragistas inglesas (Santiago, Ediciones del Memch) 113 pp.

(1957): El recurso de amparo frente a los regimenes de emergencia (Santiago, San Francisco) $278 \mathrm{pp}$.

(1959): "Algunos adagios, aforismos y principios citados en nuestra jurisprudencia": Revista de Derecho y Jurisprudencia, t. 56, pp. 149-163.

(1959): Diccionario de jurisprudencia chilena: recopilación de conceptos y definiciones (2a edición, Santiago, Jurídica de Chile) 2 vol., 346 pp., editado por Mario Verdugo Marinkovic (vol. 1: 1904-1957; vol. 2: 1958-1983), Santiago: Jurídica Ediar-ConoSur, 1984; reimpr. o 3a ed., 1986

\section{SOBRE ELENA CAFFARENA DE JILES}

ELTIT, Diamela (2003): Elena Caffarena: un siglo, una mujer (Santiago, Departamento de Comunicaciones, Servicio Nacional de la Mujer) 47 pp.

Poblete De Espinosa, Olga (1993): Una mujer, Elena Caffarena (Santiago, Cuarto Propio) 110 pp.

\section{JURISPRUDENCIA CITADA}

Catalán con Pavez (1950): Corte Suprema, 26 de agosto de 1950 (casación en el fondo), Revista de Derecho y Jurisprudencia, t. 48, Sección 1a, p. 479.

Basualto con Grandona (1951): Corte de Chillán, 6 de abril de 1951, Revista de Derecho y Jurisprudencia, t. 48, Sección 2a, p. 25.

Basso de Sampen con Sampen (1937): Corte Suprema, 10 de junio de 1942 (casación en el fondo), Revista de Derecho y Jurisprudencia, t. 40, Sección 1a , p. 46.

Montes con Roldán (1948): Corte Suprema, 17 de diciembre de 1948 (casación en el fondo), Revista de Derecho y Jurisprudencia, t. 46, Sección 1ª, p. 260.

Schortz de Coleman con Coleman (1939): Corte Suprema, 31 de julio de 1944 (casación en el fondo), Revista de Derecho y Jurisprudencia, t. 42, Sección 1a , p. 220. 